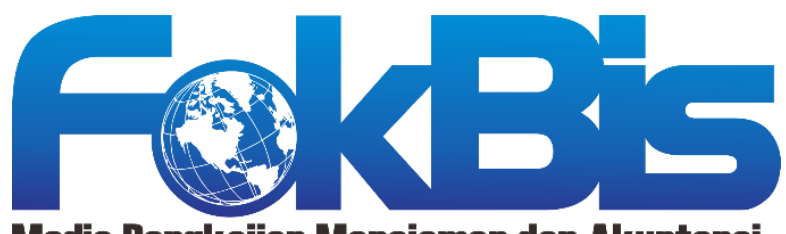

Media Pengkajian Manajemen dan Akuntansi

http://journal.stieputrabangsa.ac.id/index.php/fokbis/index

ISSN: 2623-2480/ P-ISSN: 1693-5209

\section{Pengaruh Motivasi Intrinsik, Motivasi Ekstrinsik dan Komitmen Pelayanan Tenaga Kesehatan Terhadap Kualitas Pelayanan BPJS Kesehatan}

\author{
Much. Riyadus Solichin ${ }^{1}$, Kabul Trifiyanto ${ }^{2}$ \\ ${ }^{1,2)}$ Sekolah Tinggi IImu Ekonomi Putra Bangsa, Kebumen \\ email: riyad.kroya@gmail.com
}

Article Information

History of Article:

Received: December $17^{\text {th }} 2019$

Accepted: July $16^{\text {th }} 2020$

Published: July $31^{\text {st }} 2020$

\section{DOI:}

10.32639/fokusbisnis.v19i1.407

\begin{abstract}
ABSTRAK
Penelitian ini bertujuan untuk mengetahui pelayanan tenaga kesehatan di rumah sakit swasta dalam melayani pasien yang menggunakan BPJS kesehatan. Adapun yang menjadi latar belakang penulisan ini karena sekarang pandangan pasien BPJS terhadap pelayanan kesehatan kurang baik terlebih lagi di rumah sakit swasta, ditandai dengan adanya isu di media elektronik tentang keluhan masyarakat bahwa ada perbedaan pelayanan kesehatan yang diberikan rumah sakit umum dibandingkan dengan pasien BPJS dimana pihak rumah sakit umum lebih mengutamakan pasien umum dibandingkan pasien peserta BPJS kesehatan. Penelitian ini merupakan penelitian kuantitatif yang dilakukan melalui survey dan pengisian kuisioner. Dalam penelitian ini melibatkan 90 responden pada 9 rumah sakit swasta yang merupakan penyedia jasa yang bekerjasama dengan BPJS di Kabupaten Kebumen dengan menggunakan teknik pengambilan sampling purposive sampling. Data yang terkumpul diolah dengan menggunakan software SPSS versi 22 dan dianalisis dengan menggunakan analisis regresi berganda. Hasil penelitian ini menunjukkan bahwa motivasi intrinsik dan komitmen berpengaruh terhadap kualitas pelayanan, namun tidak dapat dibuktikan pengaruh motivasi ektstrinsik terhadap kualitas pelayanan.
\end{abstract}

Kata kunci: Pelayanan Tenaga Kesehata; Motivasi Intrinsik; Motivasi Esktrinsik; Komitmen

\title{
PENDAHULUAN
}

Kewajiban Rumah Sakit bekerjasama dengan BPJS Kesehatan (UU Nomor 36/2009), serta pelayanan yang berkualitas merupakan suatu tuntutan yang tidak bisa dihindari. Badan Penyelenggara Jaminan Sosial (BPJS) adalah badan hukum publik yang dibentuk untuk menyelenggarakan program jaminan sosial yang terdiri dari BPJS Kesehatan dan BPJS Ketenagakerjaan, sehingga pasien yang terdaftar menjadi peserta BPJS Kesehatan wajib dilayani dengan baik. Maka rumah sakit membutuhkan SDM yang professional dalam melaksanakan tugas pokok dan fungsi yang merupakan tanggungjawab tenaga medis 
dalam melayani pasien sedangkan motivasi merupakan suatu proses dimana kebutuhan-kebutuhan mendorong seseorang untuk melakukan serangkaian kegiatan yang mengarah ke tercapainya suatu tujuan tertentu.

Penelitian ini bertujuan untuk menganalisis motivasi intrinsik, motivasi ekstrinsik dari para tenaga kesehatan dirumah sakit serta komitmen tenaga kesehatan terhadap kualitas pelayanan BPJS kesehatan di Rumah Sakit. Rumah sakit yang menjadi objek penelitian adalah seluruh rumah sakit Kebumen yang bekerjasama dengan BPJS yaitu berjumlah 12 RS. Namun data yang dapat dikumpulkan sebanyak 9 Rumah Sakit. Data empiris disajikan guna membuktikan bahwa kualitas pelayanan BPJS kesehatan dipengaruhi oleh motivasi intrinsik dan ekstrinsik serta komitmen yang dimiliki oleh tenaga kesehatan. Analisis regresi berganda melalui program SPSS digunakan sebagai alat uji penelitian. Data penelitian diperoleh dari Tenaga Kesehatan, Rumah Sakit Swasta dan Dinas Kesehatan untuk menguji secara ilmiah apakah kualitas pelayanan BPJS kesehatan dipengaruhi oleh motivasi intrinsik dan ekstrinsik serta komitmen tenaga kesehatan mempengaruhi kualitas pelayanan. Metode yang dilakukan pada penelitian ini adalah analisis regresi berganda. Hasil yang diperoleh adalah motivasi intrinsik dan komitmen organisasi berpengaruh terhadap kualitas pelayanan. Sedangkan motivasi ektrinsik terbukti tidak berpengaruh.

\section{LANDASAN TEORI}

Motivasi dapat diartikan juga sebagai daya pendorong (driving force) yang menyebabkan orang berbuat sesuatu atau diperbuat karena takut akan sesuatu. Misalnya ingin naik pangkat atau naik gaji, maka perbuatannya akan menunjang pencapaian keinginan tersebut (Hasibuan, 2005). Herzberg mengembangkan teori motivasi dua faktor. Menurut teori ini ada dua faktor yang memengaruhi kondisi pekerjaan seseorang, yaitu faktor pemuas (motivation faktor) yang disebut juga dengan satisfier atau instrinsik motivation dan faktor kesehatan (hygienes) yang juga disebut disatisfier atau ekstrinsic motivation (Handoko, 2000).sedangkan pengertian Tenaga Kesehatan adalah setiap orang yang mengabdikan diri dalam bidang kesehatan serta memiliki pengetahuan dan / atau ketrampilan melalui pendidikan dibidang kesehatan yang untuk jenis tertentu memerlukan kewenangan untuk melakukan upaya kesehatan.

BPJS kesehatan dalam hal ini dimaksudkan sebagai badan penyelenggara program kesehatan tidak sendiri dalam melaksanakan tugas, melainkan dibantu dan bekerjasama dengan fasilitas kesehatan yang mendukung program JKN-KIS agar dapat secara maksimal memberikan layanan kesehatan.

Komitmen antara lain; perasaan identifikasi dengan misi organisasi, perasaan terlibat dengan tugastugas organisasi, serta loyalitas dan kecintaan terhadap organisasi sebagai tempat untuk hidup dan bekerja (Dessler:1997). Sedangkan menurut Robbins (2006) mendefinisikan bahwa komitmen adalah keadaan dimana karyawan memihak pada satu organisasi dan tujuan-tujuannya, serta berniat untuk memelihara keanggotaannya dalam organisasi tersebut. jenis-jenis komitmen antara lain ; komitmen sikap, komitmen perilaku.

Terdapat 5 (Lima) dimensi pokok yang menjadi penilaian masyarakat menurut Parasuraman, et all, 1988 yaitu Tangibless, Realibility, Responsiveness, Assurance, dan Empati. Dalam kegiatan pelayanan kesehatan, diharapkan tenaga kesehatan yang menjadi bagian penting dalam fasilitas kesehatan harus memiliki kemampuan dan penguasaan terhadap penegakan diagnostik, gejala, penatalaksanaan komprehensif dan paripurna dalam pelayanan, karena terdapat dua unsur penting dalam peningkatan kualitas pelayanan kesehatan yakni tingkat kepuasan pasien dan standar pelayanan. 


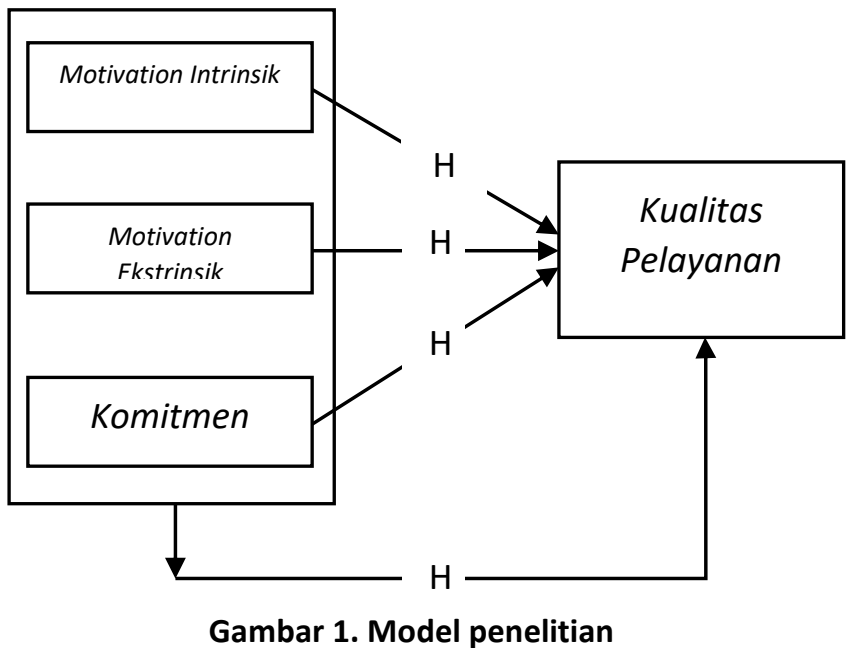

\section{METODE PENELITIAN}

Penelitian ini merupakan penelitian kuantitatif yang dilakukan melalui survey dan pengisian kuisioner. Dalam penelitian ini melibatkan 90 responden pada 9 rumah sakit swasta yang merupakan penyedia jasa yang bekerjasama dengan BPJS di Kabupaten Kebumen.

Penelitian dilakukan dalam rentang waktu bulan Mei sampai dengan Juli 2019, mencakup 9 Rumah Sakit Swasta diKabupaten Kebumen. Populasi dan sampel penelitian ini adalah 90 responden dari 9 Rumah Sakit Swasta di Kabupaten Kebumen yang melayani BPJS Kesehatan. Alat pengumpulan data yang dilakukan dengan menggunakan metode wawancara, yaitu dengan memberikan pertanyaan secara lisan kepada subyek penelitian. Metode kuesioner atau angket, yaitu metode yang dilakukan dengan menyebarkan kuesioner kepada subyek penelitian dengan menggunakan skala likert.

Data diambil dari kuesioner yang sudah terisi dari tenaga medis yang berjumlah total 90 tenaga medis dari masing-masing Rumah Sakit Swasta sejumlah 10 tenaga medis, dengan menggunakan purposive sampling. Instrument data yang sudah diolah dan sudah lolos uji validitas dan reliabilitas akan langsung diolah pada proses selanjutnya.

\section{Teknik Analisis Data}

Teknik analisis data dalam penelitian ini yaitu dengan menggunakan program SPSS Ver.22.0 (statistical product and services solutions).

a. Uji Validitas: Menurut Ghozali (2009: 49) uji validitas digunakan untuk mengukur sah atau valid tidaknya suatu kuesioner. Berdasarkan dengan ketentuan bahwa alat ukur atau item butir kuesioner dinyatakan valid apabila nilai corrected item total correlation adalah lebih besar bila dibandingkan dengan $r$ tabel dengan tingkat signifikan lebih kecil dari 0,05 dengan dasar pengambilan keputusan (Ghozali, 2009: 50).

b. Uji Reliabilitas: Menurut (Ghozali, 2009: 45) reliabilitas sebenarnya adalah alat untk mengukur suatu kuesioner yang merupakan indikator dari variabel atau konstruk. Suatu konstruk atau variabel dikatakan reliabel apabila nilai Cronbach's Alpha $>0,60$ dan apabila nilai Cronbach's Alpha $<0,60$ maka instrument dapat dikatakan tidak reliabel. 
c. Uji Asumsi Klasik

d. Uji Hipotesis: Uji hipotesis untuk menguji koefisien regresi secara keseluruhan maupun sendirisendiri pengaruh variabel independent terhadap variabel dependent menggunakan uji t. Ghozali, (2009: 88) uji t pada dasarnya menunjukkan seberapa jauh pengaruh satu variabel independen secara individual dalam menerangkan variasi variabel dependen.

e. Koefisien Determinasi (R2): Menurut Ghozali (2009: 87) koefisien determinasi (R2) digunakan untuk mengukur seberapa jauh kemampuan model dalam dalam menerangkan variasi variabel dependen.

f. Analisa Regresi Linear Berganda

\section{HASIL DAN PEMBAHASAN}

The population in this study were all SMEs in Kebumen. Samples are businesses that have a workforce of more than ten people. Furthermore, the sampling technique that is also used is purposive sampling technique that is deliberate sampling. That is, researchers determine their own samples taken because there are certain considerations. (Sugiyono, 2009). The number of samples is determined by the characteristics of a workforce of more than 10 people as many as 100 business units. Of the 125 instruments distributed, 100 can be used for analysis.

\section{Uji Asumsi Klasik}

Tabel 1. Uji Multikolinearitas

\begin{tabular}{|c|c|c|c|c|c|c|c|c|}
\hline \multirow[b]{2}{*}{ Mode } & & \multicolumn{2}{|c|}{ Unstandardized Coefficients } & \multirow{2}{*}{$\begin{array}{l}\text { Standardized } \\
\text { Coefficients } \\
\text { Beta } \\
\end{array}$} & \multirow[b]{2}{*}{$t$} & \multirow[b]{2}{*}{ Sig. } & \multicolumn{2}{|c|}{ Collinearity Statistics } \\
\hline & & $\mathrm{B}$ & Std. Error & & & & Tolerance & VIF \\
\hline \multirow[t]{4}{*}{1} & (Constant) & 18,682 & 3,761 & & 4,967 &, 000 & & \\
\hline & $\mathrm{X} 1$ &, 510 & ,222 & ,269 & 2,292 & ,024 & ,675 & 1,480 \\
\hline & $\mathrm{X} 2$ &, 006 & ,197 & ,004 & ,029 & ,977 &, 553 & 1,808 \\
\hline & X3 & ,401 &, 162 & ,279 & 2,470 &, 015 & ,726 & 1,378 \\
\hline
\end{tabular}

Sumber: Data diolah (2019)

Berdasarkan tabel 1 dapat disimpulkan bahwa tidak terdapat gejala multikolonieritas. Berdasarkan tabel 1 di atas, dilihat bahwa nilai variance inflation factor (VIF) dari masing-masing variabel independent adalah 1,480 kurang dari 10 dan nilai tolerance yang terbentuk adalah 0,675 diatas 0,1 maka dapat disimpulkan bahwa model regresi layak digunakan untuk penelitian selanjutnya dan tidak terdapat multikolinearitas 


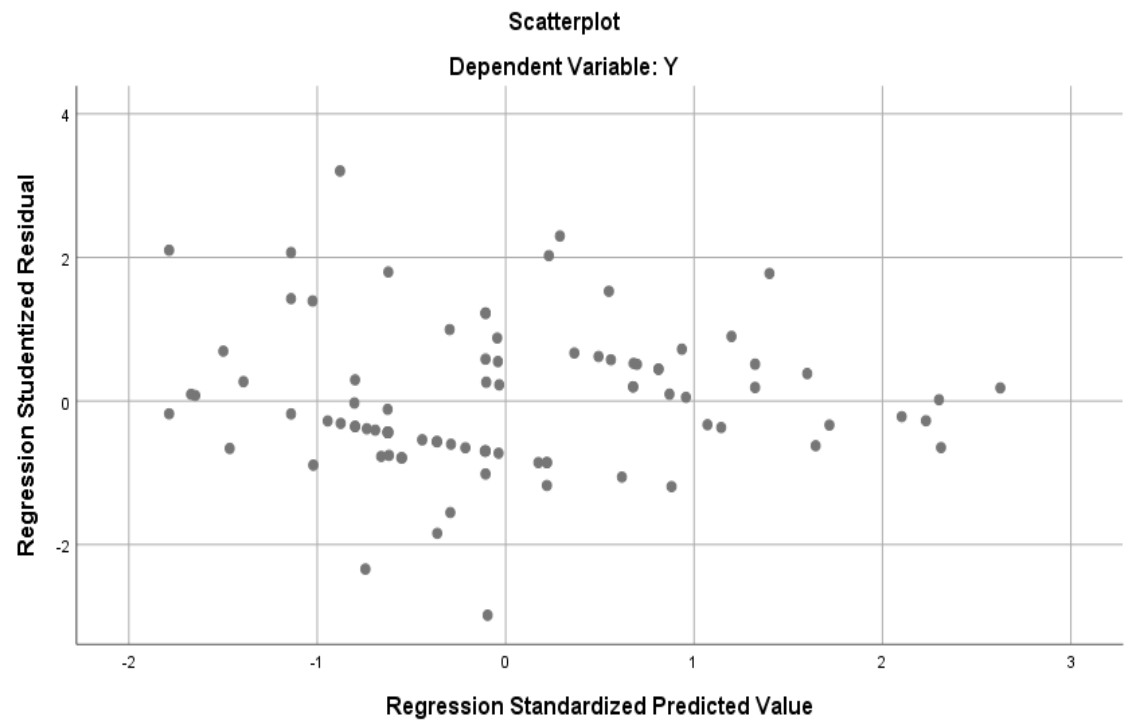

Gambar 2. Uji Heteroskedasitias

Berdasarkan uji heterokedastisitas menggunakan diagram scatter plot dapat disimpukan bahwa lolos uji karena titik-titik tidak membentuk pola tertentu. Sehingga persamaan regresi dapat dilanjutkan.

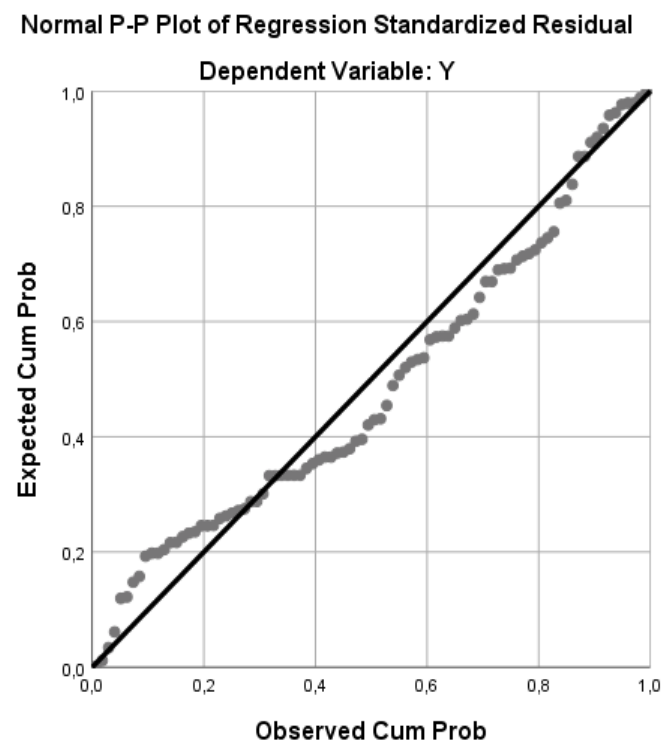

Gambar 3. Uji Normalitas

Berdasarkan Gambar 2 dapat disimpulkan bahwa data lolos uji normalitas karena titik-titik mengikuti diagonal. 


\section{Hasil Uji-t}

Alat analisis ini digunakan untuk menjawab hipotesis yang sudah dibuat. Hasil pengolahan SPSS untuk uji t ditunjukkan pada tabel berikut:

Tabel 2. Hasil Uji t

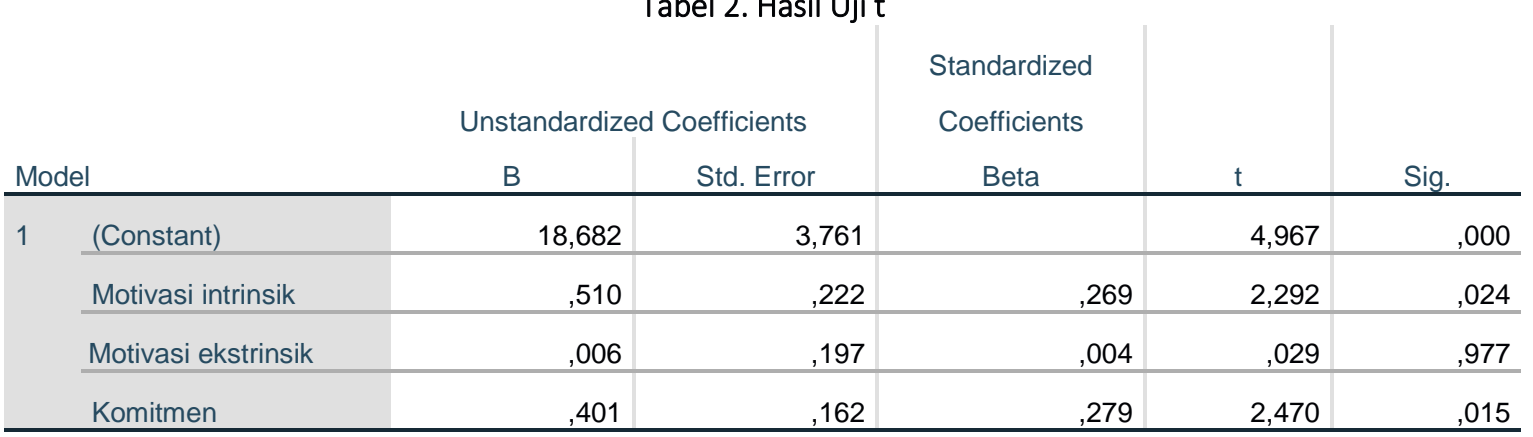

Sumber: Data diolah (2019)

Dari tabel 2 diperoleh nilai t hitung untuk variabel motivasi intrinsik sebesar 2,292 lebih besar dari t tabel 1,198 dengan nilai signifikansi sebesar 0,024 < 0,05 sehingga dapat disimpulkan hipotesis diterima. nilai t hitung untuk variabel motivasi ekstrinsik sebesar 0,029 lebih kecil dari t tabel 1,198 dengan nilai signifikansi sebesar 0,977>0,05 sehingga dapat disimpulkan hipotesis ditolak. nilai thitung untuk variabel komitmen sebesar 2,470 lebih besar dari t tabel 1,198 dengan nilai signifikansi sebesar 0,015 $<0,05$ sehingga dapat disimpulkan hipotesis diterima.

Dari tabel tersebut dapat ditarik persamaan regresi sebagai berikut:

$$
Y=0,510 \times 1+0,006 \times 2+0,401 \times 3+e
$$

\section{Hasil Uji-F}

Alat ini digunakan untuk mengetahui pengaruh variabel independen terhadap variable dependen secara simultan. Hasil dari SPSS uji f sebagai berikut:

Tabel 3. Hasil uji F

\begin{tabular}{|c|c|c|c|c|c|c|}
\hline Model & & Sum of Squares & df & Mean Square & $\mathrm{F}$ & Sig. \\
\hline \multirow[t]{3}{*}{1} & Regression & 218,162 & 3 & 72,721 & 7,271 &, $000^{\mathrm{b}}$ \\
\hline & Residual & 860,161 & 86 & 10,002 & & \\
\hline & Total & 1078,322 & 89 & & & \\
\hline
\end{tabular}

a. Dependent Variable: $Y$

b. Predictors: (Constant), X3, X1, X2

Sumber: Data diolah (2019)

Dari penghitungan statistik menggunakan SPSS diperoleh hasil nilai $F$ hitung sebesar 7,271 dengan tingkat signifikansi sebesar 0,000. Rumusan hipotesis menunjukkan jika $F$ hitung $>F$ tabel $(7,271>$ $2,71)$ maka hipotesis diterima. Sehingga dapat disimpulkan bahwa semua variable bebas secara bersama-sama berpengaruh terhadap kualitas pelayanan. 


\section{Hasil Uji Determinasi}

Nilai Adjust R square menunjukkan seberapa besar pengaruh variabel independentterhadap variabel dependent. Dalam penelitian ini dihasilkan nilai R square sebagai berikut:

\begin{tabular}{|c|c|c|c|c|}
\hline \multicolumn{5}{|c|}{ Tabel 4. Hasil uji determinasi } \\
\hline Model & $\mathrm{R}$ & R Square & Adjusted R Square & $\begin{array}{l}\text { Std. Error of the } \\
\text { Estimate }\end{array}$ \\
\hline 1 & $450^{a}$ & ,202 &, 174 & 3,163 \\
\hline
\end{tabular}

a. Predictors: (Constant), X3, X1, X2

Sumber: Data diolah (2019)

Dari tabel 4 dapat diketahui besaran variasi variabel dependent yang dipengaruhi oleh variabel independent adalah sebesar $45 \%$, sedangkan sisanya dipengaruhi oleh faktor lain diluar penelitian ini. Hal ini menunjukkan bahwa masih ada $55 \%$ factor lain yang mempengaruhi kualitas pelayanan

\section{SIMPULAN DAN SARAN}

Berdasarkan analisis bagian sebelumnya pada penelitian ini, maka dapat ditarik kesimpulan sebagai berikut:

a) Motivasi intrinsik berpengaruh terhadap kualitas pelayanan tenaga kerja di rumah sakit swasta. Sehingga apabila motivasi pelayanan tenaga medis meningkat, kualitas pelayanan yang diberikan pun meningkat.

b) Motivasi ekstrinsik tidak berpengaruh terhadap kualitas pelayanan tenaga kerja di rumah sakit swasta. Sehingga apabila motivasi ekstrinsik pelayanan tenaga medis meningkat/menurun, tidak dapat menstimuli kualitas pelayanan yang diberikan.

c) Komitmen berpengaruh terhadap kualitas pelayanan tenaga kerja di rumah sakit swasta. Sehingga apabila komitmen pelayanan tenaga medis meningkat maka kualitas pelayanan yang diberikan meningkat.

d) Motivasi intrinsik, motivasi ekstrinsik dan komitmen secara bersama-sama berpengaruh terhadap kualitas pelayanan tenaga kerja di rumah sakit swasta. Sehingga motivasi pelayanan tenaga medis dapat menstimuli kualitas pelayanan yang diberikan.

Bagi penelitian selanjutnya dapat menambah variabel selain Motivasi Intrinsik, Motivasi Ekstrinsik dan Komitmen terhadap Kualitas Pelayanan. Implikasi dan dampak penelitian ini adalah diharapkan bisa memberikan kontribusi terhadap pelayanan rumah sakit terutama tenaga kesehatan khususnya BPJS kesehatan, agar tetap termotivasi memberikan pelayanan yang terbaik kepada masyarakat. Kendala penelitian dilapangan yang terjadi diantaranya terkait ijin penyebaran kuesioner pada pihak rumah sakit tidak lolos sesuai harapan dan jarak antara rumah sakit swasta satu dengan lainnya berjauhan. 


\section{REFERENSI}

Ardini, L. (2010). Pengaruh Kompetensi, Independensi, Akuntabilitas dan Motivasi Terhadap Kualitas Audit. Jurnal Ekonomi dan Bisnis Airlangga (JEBA)/ Journal of Economics and Business Airlangga, 20(3).

Foot, M., \& Hook, C. (2008). Introducing human resource management. Pearson Education, 130-147.

Ghozali, I. (2009). Ekonometrika: teori, konsep dan aplikasi dengan SPSS 17. Semarang: Badan Penerbit Universitas Diponegoro.

Handoko H. (2000). Manajemen Personalia Sumber Daya Manusia. BPFE UGM. Yogyakarta.

Hasibuan, M. S. (2005). Manajemen Sumber Daya Manusia, PT. Bumi Aksara, Jakarta.

Herzberg, F., (2006). Work and the Nature of Man. New York: Thomas Y. Crowell Co.

Parasuraman, A., Zeithaml, V. A., \& Berry, L. L. (1988). Servqual: A multiple-item scale for measuring consumer perc. Journal of retailing, 64(1), 12-40.

Ratifah, I., \& Ridwan, M. (2014). Komitmen organisasi memoderasi pengaruh sistem akuntansi keuangan daerah terhadap Kualitas Laporan Keuangan. Trikonomika Journal, 11(1), 29-39.

Robbins, S. P., \& Judge, T. A. (2006). Perilaku organisasi. Edisi kesepuluh. Jakarta: PT Indeks Kelompok Gramedia.

Undang-Undang Republik Indonesia Nomor 36 Tahun 2009 tentang Kesehatan. 